\title{
1.04
}

\section{Derecho a la Salud ¿Derecho social, derecho civil o derecho cultural?}

Right to health: social right, civil right or cultural right?

\section{Agustín Carignani}

Abogado. Especialista en Derecho Sanitario, Diplomado en Derecho a la Salud. Profesor Invitado de la Facultad de Derecho y Ciencias Sociales de la Uiversidad Nacional de Cordoba. Argentina.

\section{José Emilio Ortega}

Abogado. Especialista en Gestión Administrativa de la Salud Pública, Curso de Posgrado. Profesor de Derecho Público Provincial y Municipal y de Derecho a la Salud de la Facultad de Derecho y Ciencias Sociales de la Universidad Nacional de Cordoba. Co-Fundador del Centro de Investigación y Formación de Salud Ambiental (UNC). Cordoba, Argentina.

\section{Federico Robledo (h)}

Abogado. Magister en Bioética, Diplomado en Derecho a la Salud. Prof. de Derecho Constitucional, Derecho Público Provincial y Municipal y Derecho a la Salud de la Facultad de Derecho y Ciencias Sociales de la Universidad Nacional de Cordoba. Argentina.

Resumen: Abordase la relación dialéctica entre el Estado y la sociedad en aras de proteger y garantizar un acceso igualitario a la salud pública, teniendo en vista la necesidad de dicho acceso como derecho humano fundamental, como asimismo la extrema necesidad de que el sistema público de salud sea sustentable. Para ello, se parte de un concepto básico de salud, recorriendo un camino constructivo conceptual.

Palabras claves: Derecho a la salud; Salud Pública; Minimun Garantizable; Mínimo existencial

Key-words: Right to health, Public Health, Warranted Minimum, Existential Minimum

\section{Introducción: El derecho a la salud en Argentina}

La "salud" constituye un derecho fundamental de raigambre constitucional, inscripto en el articulado del bloque de constitucionalidad federal (art. 75 inc. 22 C.N.), en su triple dimensión: normativa, sociológica e histórica. ${ }^{1}$

\footnotetext{
1 Adoptamos un concepto amplio y multidimensional de Constitución - en Argentina, bloque de constitucionalidad - tras haber sido investidos de rango normativo supremo a un grupo de tratados
} 
Ahondando en este punto, destacamos que en la Constitución originaria de 1853/60, revestía el carácter de derecho implícito con asiento normativo en el art. 33 de la C.N. - derechos no enumerados-.

Recién fue explicitado, a partir de la reforma constitucional de 1949, dejada sin efecto y resumida en el art. 14 bis. en el año 1957, por el influjo del constitucionalismo social, iniciado por las cartas fundamentales de México (1917) y Weimar (1919).

Siguiendo a Reynaldo Mapelli Junior (2012, p. 15) estos derechos:

vinieron a surgir con la nueva conformación del Estado, que dejó de actuar como una meragarantía de derechos individuales (Estado liberal) y abrazó la función de proveer a los ciudadanos prestaciones positivas volcadas a la satisfacción de sus necesidades básicas (Estado social).

De lo que planteamos supra, vemos con claridad que estos derechos sociales, están estrechamente ligados a los derechos humanos, ya que éstos se corresponden con los principios morales que deben dar la garantía de satisfacción de las condiciones mínimas para la realización de una vida digna (Ferreira da Rocha, 2008, p. 21).

Sin perjuicio de lo expresado, recién adquiere una consagración integral en la reforma de 1994, tanto en la Carta Magna Federal como en los Tratados Internacionales de Derechos Humanos que amplían el estatuto de derechos fundamentales y desarrollan los despliegues e interrelaciones de la salud con otros derechos.

Ahora bien, teniendo en cuenta que lo que aquí se pretende es establecer la dimensión del concepto de salud, por cuanto de ello se sigue la determinación del alcance y contenido del derecho sub examine, resulta imperioso formular algunas reflexiones y consideraciones sobre el tópico.

En este sentido, ponemos de resalto que el concepto de salud es un concepto evolutivo, que ha ido modificándose y ensanchándose a lo largo de la historia y aún en la hora actual.

En la historia reciente, a principios del Siglo XX, se la concepción desde una acepción muy limitada como ausencia de dolencias, lo que se documenta, por ejemplo, con el importante antecedente de Márcia Faría Westphal (apud Mapelli, 
2012, p. 16) tras descubrir la insulina en los años 1930. Poco tiempo después, se observó que la salud no sólo consiste en la ausencia de enfermedades, sino más bien, en las múltiples relaciones que presenta el la salud con la comunidad y hasta con el medio ambiente, lo que quedaría definitivamente estatuído en el preámbulo de la Constitución de la Organización Mundial de la Salud (1948), en el que se la define como un estado de completo bienestar físico, mental y social y no sólo la ausencia de enfermedades" (OMS, 2006).

Este cambio paradigmático se inscribe en un cambio de la cultura y cosmovisión de la salud y de la persona humana, que se viera alentado el avance de la ciencia y tecnología y su impacto en la medicina.

En la hora actual, los nuevos interrogantes de la salud se ubican entre lo "científicamente posible, éticamente aceptable y jurídicamente permitible" (Avila Paz de Robledo, 2010, p. 132).

De este modo, protección de la salud se 'fue universalizado y recogido en diferentes tratados internacionales de derechos humanos, firmados por prácticamente todas las naciones del mundo" (Aith, 2011, p. 14) y que, como referimos supra, la República Argentina elevó al mismo rango que su Constitución, dándole jerarquía suprema.

Con ello, también surgen sistemas regionales y organismos universales que supervisan el cumplimiento de los tratados y actúan como instancias supranacionales consultivas y contenciosas para la resolución de controversias en la materia.

\subsection{El derecho a la salud en la sociedad.}

Siguiendo a Fernando Aith (2011, p. 30) tenemos que reconocer los deberes que pesan sobre la sociedad para la protección del derecho a la salud, ya que para garantizar este derecho, es necesario el esfuerzo de toda la sociedad. Estos deberes: engloban los deberes de las familias, asociaciones de barrios, organizaciones no gubernamentales, empresas entre otros actores sociales relevantes, de participar activamente en las campañas y las actividades de protección de la salud.

Estos deberes sociales se traducen en innúmeras actividades; empresas que sean ambientalmente saludables, la alimentación apropiada en el seno de la familia, higiene personal, el tratamiento de residuos, la responsabilidad social, etc. Y ello no puede ser de otra manera, dado que las condiciones en que las personas viven y trabajan, impactan directamente sobre la salud de las personas. Son conocidos como 
determinantes sociales. Estos determinantes sociales objeto de políticas públicas son aquellos susceptibles de modificación mediante intervenciones efectivas (OMS, 2008).

En este contexto, debemos preguntarnos el alcance de este derecho, reconocido ampliamente como un derecho social fundamental.

\subsection{El derecho a la salud como derecho social fundamental.}

Siguiendo a Bonavides (2004, p. 574), decimos que fue a partir de la Declaración Universal de los Derechos Humanos que "el humanismo político de la libertad alcanzó su punto más alto del siglo XX. Se trata de un documento de convergencia y al mismo tiempo de una síntesis".

Pero cuando nos interrogamos sobre cuál es la naturaleza jurídica de estos derechos sociales, Marmelstein (2008, p. 51) opina que son aquellos que "imponen directrices, deberes y tareas a ser realizadas por el Estado, con el propósito de posibilitar a los seres humanos mejor calidad de vida y un nivel razonable de dignidad como presupuesto del propio ejercicio de la libertad". Es justamente en este sentido, en que la doctrina entiende que en los derechos de segunda generación, es necesario un actuar positivo del Estado a través de sus distintos órganos y según sus esferas de gobierno (Macedo Y Barreto e Silva, s/d). Este Estado, debe garantizar las herramientas para un mínimo de bienestar de la persona humana, cuyo mínimo se traduce en educación, salud, entre muchas otras.

Es así como necesitamos conocer entonces, esa dicotomía existente entre estos derechos de segunda generación o derechos sociales, y distinguirlos patentemente de los derechos civiles. Y para poder trazar una línea clara que nos ayude en este aspecto, decimos que los derechos sociales o de segunda generación:

"diversamente de los derechos de primera generación, (...) son concebidos como instrumentos destinados a la efectiva reducción y/o supresión de desigualdades, según la regla de que se debe tratar igualmente a los iguales y desigualmente a los desiguales, en la medida de su desigualdad (Mendes et al., 2008, p. 710).

En este contexto que venimos demarcando de los derechos sociales, y por qué no decirlo, del derecho a la salud, que es particularmente aquel que nos convoca en este artículo, no podemos soslayar que la doctrina dista mucho de ser unánime en cuanto al alcance del deber del Estado para garantizar la operatividad y realización de los derechos sociales, y particularmente, el derecho a la salud. 
Asimismo, los titulares del derecho sub examine han incrementado exponencialmente en los últimos cuarenta años los reclamos administrativos y judiciales para la cobertura de su salud. Ello ha dado lugar a la judicialización de salud y, dentro de este fenómeno, la amparización, cautelarización y búsqueda de nuevos andariveles procesales que permitan brindar una tutela jurisdiccional efectiva, tempestiva y adecuada. En este sentido, en el último precedente en la materia de la C.S.J.N., "Pardo, Hector Paulino y otro c/ Di Césare, Luis Alberto y otro s/ art. 250 del C.P.P. 06/12/2011”, el tribunal cimero fijó como un estándar de protección, poner el acento en el valor "eficacia" de la función jurisdiccional y en el carácter instrumental de las normas procesales, en el sentido de que su finalidad radica en hacer efectivos los derechos sustanciales y, especialmente, el derecho a la salud.

En nuestra opinión, ponderamos positivamente el diseño y creación de sistemas de salud, como instrumento para mejorar la cobertura y prestación del bien público referenciado, mediante la gestión pública integrada estratégica e inteligentemente con los sectores privados. Sin perjuicio de ello, no podemos soslayar que el Estado - nacional, provincial y municipal - ejerce la rectoría de dicho sistemas, pero al mismo tiempo constituye el garante último de su efectiva tutela y protección. Va de suyo, la importancia de la labor del estado en la realización del derecho en una etapa prejurisdiccional.

No podemos dejar de apuntar, que el constitucionalismo de tercera generación ha influido en la definición de este derecho, que además de ser un derecho individual, también puede serlo de incidencia colectiva (art. 43 C.N.), lo que abre en el campo del derecho procesal nuevas vías, como las class actions y procesos colectivos, con legitimación procesal amplia para incoar reclamos en la materia -que incluyen tanto a los afectados como Asociaciones Civiles y el Defensor del Pueblo - y el efecto expandido de la cosa juzgada.

\section{El mínimo existencial y reserva de lo posible}

La característica propia de los derechos sociales que los hace tan irrefutables prima facie, es justamente que ellos, son aquellos derechos que están estrictamente vinculados a los valores más elementales de la persona humana, es justamente que son aquellos derechos fundamentales que están íntimamente ligados con los derechos de la dignidad humana. 
La teoría del mínimo existencial fue acuñada en Alemania (1948), como una tentativa dirigida a garantizar un mínimo de derecho reconocido a las personas por el Estado alemán. Esta teoría sustenta que el mínimo existencial ligado a la dignidad humana, no estaría resumido a la cuestión de la libertad, sino un principio de seguridad social como la salud, educación, vivienda etc. (Torres, 2008).

"Este término de mínimo existencial también es conocido como "contenido mínimo", "mínimo vital", núcleo esencial", "substancia mínima" de los derecho sociales" (Cunha, 2010, p. 82).

El derecho a las condiciones mínimas de existencia de la persona humana es inherente a ésta, de forma que condiciona el ordenamiento jurídico y se sustancia en un derecho público subjetivo (Torres, 1989).

Sin embargo, este alcance de estos derechos, como ya lo adelantáramos, no es unánime y dista mucho de serlo. Para explicar esto, haremos una breve referencia a la teoría del mínimo existencial y los fundamentos doctrinarios de cada corriente de la misma.

Una de estas corrientes, es aquella que establece que para poder garantizar los derechos sociales, y procurando garantizar la eficacia de los mismos, reduce el alcance de estos derechos al mínimo existencial. Este mínimo existencial consiste justamente en "la cantidad mínima de derechos sociales debajo de los cuáles el hombre no tiene condiciones para sobrevivir con dignidad" (Torres, 2008, p. 53).

Ana Paula Barcellos (2001, p. 304) entiende que ese mínimo existencial consiste en:

lo vinculado a los elementos materiales de la dignidad, es compuesto de un mínimo existencial que consiste en un conjunto de prestaciones materiales mínimas sin las cuáles se podrá afirmar que el individuo se encuentra en situación de indignidad.

Los detractores de esta teoría, hacen hincapié en que en una sociedad Democrática propia de los países sudamericanos (vgr. Argentina y Brasil), esta teoría no coincide con el contexto socio económico, político y cultural, ya que el mínimo existencial no puede tener un contenido establecido a priori frente a su relativización (Jorge Neto, 2008).

Es así que encuentran la explicación en la necesidad de que el Estado garantice estos derechos a ultranza a todas las personas sin posibilidades de "relativizar" este derecho bajo pretexto alguno, llevando a estos derechos de segunda generación al nivel de aquellos derechos civiles y políticos de primera generación 
como una parte de estos, como esenciales a la dignidad de la persona humana; y fundamentando legalmente en los Tratados y Acuerdos Internacionales que han sido firmados y ratificados por los países signatarios.

Con lo dicho, verificamos que existe un núcleo relativo a los derechos sociales, cuya efectivización encuentra obstáculo en la reserva de lo posible. Ricardo Lobo Torres (1989), realiza una compatibilización de estos conceptos, que afirma que el mínimo existencial se relaciona con el concepto de pobreza absoluta que deviene de la desigualdad social, debiendo por lo tanto ser combatida por el Estado. La pobreza relativa deviene de las causas de producción económica y la redistribución de bienes objeto de políticas presupuestarias y se fundamentan en las condiciones de justicia social.

No obstante ello, el autor parece no indicar claramente cuál es la obligación del Estado en relación a la protección del derecho a la salud, sin embargo, de los conceptos por el traídos, parecería que al Estado le cabe tomar todas las medidas tendientes a garantizar acciones preventivas y el combate de las enfermedades derivadas de la pobreza total.

En efecto, la efectivización de esos derechos, depende no sólo de la aplicación de normas constitucionales, sino también de factores económicos, de organización y funcionamiento de la Administración Pública y de los recursos financieros. No por otra cosa, el artículo 22 de la Declaración Universal liga los derechos económicos, sociales y culturales al esfuerzo nacional y a la cooperación internacional en armonía con la organización y los recursos de cada pueblo (ONU, 2012).

En Argentina, este mínimun garantizable está establecido mediante un nomenclador prestacional denominado Programa Médico Obligatorio (PMO) fijado y actualizado por el Ministerio de Salud de la Nación, de orden público y exigible tanto en la medicina prepaga y privada, como en las Obras Sociales y Salud Público.

El problema es si esta medida excluye el reclamo y protección de otras prestaciones y tratamiento no incluidos en el mismo.

\section{La salud como un derecho fundamental}

Los términos derechos del hombre y derechos humanos, ambos de connotación jusnaturalista, traducen la idea de derechos que son inherentes al ser humano. Siguiendo a Ingo W. Sarlet (2009, p. 30) la distinción didáctica entre esas expresiones posee la finalidad de delimitar una fase en la cual los llamados derechos 
del hombre aún no habían sido reconocidos por el Derecho positivo, en contraposición de los Derechos humanos entendidos como los positivados internacionalmente, sin que nada obste a que se los reconozca el mismo significado.

Cuando nos adentramos al estudio del derecho a la salud y las formas o mecanismos dispuestos a su protección, no podemos dejar de cuestionarnos ciertos interrogantes que se plantean.

Uno de ellos, es determinar cuál es el verdadero alcance del derecho a la salud, es decir, debe ser considerado como un derecho absoluto, o por el contrario, el mismo derecho reconoce limitaciones, y si es el caso, en que ocasiones?

A los fines de dilucidar semejantes interrogantes, la Corte Suprema de Justicia de la Nación ${ }^{2}$ ha dicho que:

Los derechos civiles, políticos y sociales que la Constitución nacional consagra, lejos de ser absolutos, están sujetos a limitaciones o restricciones tendientes a hacerlos compatibles entre sí, y con los que corresponde reconocer a la comunidad.

Siguiendo de esta manera con los derechos individuales frente al Estado, Gordillo (2003) interpreta que:

la constitución y las normas supranacionales no son en estos casos un programa de gobierno que puede cumplirse o no: son un orden jurídico imperativo, para el Estado y los habitantes (...). Ofrecen un equilibrio de las atribuciones que otorgan: reconocen atribuciones al Estado, pero también derechos inalterables a los individuos. Ni unos ni otros pueden tener supremacía, ambos deben armonizarse dentro del orden jurídico.

Sustentar lo contrario implicaría una concepción antisocial del derecho.

\subsection{Los derechos sociales y deberes sociales}

Tomando en consideración lo ya dicho del origen de los derechos sociales, su naturaleza jurídica y el alcance de los mismos; y trayendo a este respecto la Declaración Americana de los Derechos y Deberes del Hombre, consideramos oportuno remarcar su preámbulo:

Todos los hombres nacen libres e iguales en dignidad y derechos y, dotados como están por naturaleza de razón y conciencia, deben conducirse fraternalmente los unos con los otros. El cumplimiento del deber de cada uno es exigencia del derecho de todos. Derechos y deberes se integran correlativamente en toda actividad social y política del hombre. Si los derechos exaltan la libertad individual, los deberes expresan la dignidad de esa libertad (IX Conferencia, 1948).

\footnotetext{
${ }^{2}$ Corte Suprema de Justicia de la Nación. Fallos: 312:318; 314:225; 315:380; 320:196.
} 
Siguiendo más aún, la misma Declaración en su Capítulo Segundo "Deberes", artículo XXXV "Deberes de asistencia y seguridad sociales", establece que:

Toda persona tiene el deber de cooperar con el Estado y con la comunidad en la asistencia y seguridad sociales de acuerdo con sus posibilidades y con las circunstancias.

En este pensamiento del derecho a la salud como derecho social, tenemos que acordar que los sujetos activos del ejercicio de tal derecho está representado potencialmente por toda la sociedad, y en el polo opuesto de dicha relación, o sea, en el polo pasivo, se encuentra también potencialmente toda la sociedad.

Ahora bien, como establecemos en el párrafo que antecede, a partir del análisis estructural de los derechos humanos, se propone un concepto de derecho subjetivo en que el titular del derecho es la persona humana, y el titular del deber es el co-humano, en la acepción de la ética de la fraternidad del pensamiento tomista, que representa una explicación filosófica de la noción del cristianismo, según el cual, el titular del deber tiene su correlativo en relación a los derechos humanos, de quién se encuentra en frente a otro ser humano. En cuanto al objeto de los derechos humanos, este no es entendido como una facultad del poder subjetivo conforme propone la dogmática jurídica, ysí como lo justo subjetivo, es decir, aquello que es debido y adecuado a un miembro de la sociedad en su singularidad. Por ello, se debe mantener una relación en función del bien común, manteniéndose una correlación con los demás miembros de la sociedad (Barzotto, 2010).

Barzotto (2005) demuestra la lógica del derecho subjetivo entendido como justo, tomando como ejemplo el caso de la salud. En la perspectiva del derecho a la salud como poder subjetivo, entiende que garantizar al individuo ese derecho, implica decir que tiene la posibilidad de forzar al Estado a entregarle un tratamiento o remedio a través del proceso judicial. En ese sentido, el derecho a la salud entrega a un derecho subjetivo sobre una parte del presupuesto, sin que se tenga en cuenta el impacto que eso tendrá en relación a toda la sociedad.

Manoel Gonçalves Ferreira Filho (2006) indica que de la misma manera que las libertades públicas; los derechos sociales son derechos subjetivos, teniendo así la potestad de exigir una prestación concreta por parte del Estado. Sin embargo, la garantía que el Estado da a esos derechos, es la institución de los servicios públicos, lo que genera pesados encargos al Estado, e indirectamente, a los contribuyentes. En este marco, el autor cuestiona hasta que punto el Estado debe dar atendimiento a 
esos derechos, hasta que punto debe amparar a las personas en la busca de ese derecho, cuestionando asimismo, hasta que punto la protección judicial es efectiva?

Concluye en que la efectivización de los derechos sociales en los casos en que se reclaman políticas públicas, difícilmente se puede resolver con una acción judicial, dado que la imposición de tales políticas depende de factores que no se encuentran en el ámbito tradicional de la actuación judicial.

Por lo tanto, no es posible entender un derecho social como un derecho subjetivo en la concepción del derecho privado, en que el ciudadano es acreedor de toda y cualquier prestación en el área de la salud.

\section{La salud y su cuidado en el MERCOSUR}

Realizaremos una breve referencia al sistema legislativo de algunos de los países que conforman el bloque económico del Mercosur en relación al deber de cuidar la salud:

En Argentina, la salud tiene un plafón amplio de recepción en los Pactos y Tratados Internacionales y Constitución Nacional (artículo 75, inciso 22).

Por su parte, La República Federativa del Brasil, en su Sección II "De la Salud" artículo 196 al 200 regula sobre el derecho a la salud, y en tal sentido entiende (artículo 196):

\footnotetext{
La salud es un derecho de todos y un deber del Estado, garantizado mediante políticas sociales y económicas que tiendan a la reducción del riesgo de enfermedad y de otros riesgos y al acceso universal e igualitario a las acciones y servicios para su promoción, protección y recuperación (Brasil, 2008).
}

Profundizando este punto, destacamos que la Ley 8080/90 que viene a reglamentar la prestación de los servicios de salud reconocidos mediante la Constitución establece en su artículo $2^{\circ}$ el cual reconoce que "la salud es un derecho fundamental del ser humano, debiendo el Estado proveer las condiciones indispensables para su pleno ejercicio, en su párrafo $2^{\circ}$ dispone que "el deber del Estado, no excluye el de las personas, de la familia, de las empresas y de la sociedad" (Brasil, 1990).

Coincidimos en que este derecho también implica un deber. Siguiendo con el análisis propuesto, y en adelante siguiendo la línea de trabajo dada por Zavaley y Sommer (2011, p. 105-106) encontramos que la Constitución de Uruguay, en su artículo 44 expresa "Todos los habitantes tienen el deber de cuidar la salud, así como 
el de asistirse en caso de enfermedad", llamando la atención el hecho de que el Estado sólo proporciona los medios de prevención y asistencia a los indigentes o carentes de recursos suficientes.

Por su parte, el Paraguay con la sanción de la Constitución de 1992 en su Capítulo VI "De la Salud", particularmente en sus artículos 68 y 69. En el artículo 68 establece que "El Estado protegerá y promoverá la salud como derecho fundamental de la persona y en interés de la comunidad. Nadie será privado de asistencia pública para prevenir o tratar enfermedades [...]". Asimismo, establece que "Toda persona está obligada a someterse a las medidas sanitarias que establezca la ley, dentro del respeto a la dignidad humana". Por su parte, el artículo 69 establece que "Se promoverá un sistema nacional de salud que ejecute acciones sanitarias integradas, con políticas que posibiliten la concertación, la coordinación y la complementación de programas y recursos del sector público y privado".

Como vemos, en el marco del Mercosur, en términos del derecho al acceso a la salud, tenemos una reglamentación marcada, de diferentes maneras. Como se traduce en los casos de las Constituciones del Uruguay y del Paraguay existe una declaración taxativa del deber de cuidar la salud en el propio cuerpo de la Constitución, mientras que en el caso de la República federativa del Brasil, existe una ley infra constitucional que viene a reglamentar ese deber del Estado, no excluye el de la sociedad, de la familia y de las empresas. Y finalmente, en el caso de Argentina, encontramos que el reconocimiento de la salud se da en el marco del artículo 75 inc. 22, donde la Declaración Americana de los Derechos y deberes del Hombre; la Declaración Universal de Derechos Humanos, etc. en las condiciones de su vigencia, tienen jerarquía constitucional.

Es así que, como podemos ver en este contexto, la salud reconocida como derecho fundamental de la persona humana, es garantizada por los Estados con políticas públicas que maximizan los beneficios para el mayor número de personas y al mismo tiempo protege los derechos individuales.

\section{La construcción de la salud en forma conjunta entre sociedad y del Estado}

En el marco internacional, la salud es tenida en cuenta por múltiples Declaraciones y Pactos, que no sólo garantizan el reconocimiento y la protección de la misma sino asimismo, plantea la manera de garantizarla y prever los recursos 
necesarios para lograr dicho objetivo. Ello lo podemos advertir en los artículos 3 y 4 del Pacto Internacional de Derechos Económicos, Sociales y Culturales, en los artículos 29 y 35 de la Declaración Americana de los Derechos y Deberes del Hombre, artículos 22 y 29 de la Declaración Universal de Derechos Humanos y artículo 32 de la Convención Americana sobre Derechos Humanos. Este último tratado se completa y refuerza con el Protocolo de San Salvador.

Como se pone en evidencia, la tendencia de la construcción de la salud, dista mucho de ser una responsabilidad exclusiva de los países, para ser una construcción conjunta y necesaria entre los Estados y sus habitantes.

En este orden de ideas, coincidimos con Winslow (1920) en que la salud colectiva designa a la ciencia y al arte de prevenir enfermedades, prolongar la vida y promover la salud física y la eficiencia del individuo a través de esfuerzos organizados de la comunidad. Es precisamente ese concepto de salud que viene imponiéndose en el descorrer de los años, a través de conferencias, seminarios y encuentros nacionales e internacionales adaptándose a la realidad mundial (Moretti, 2008).

$Y$ es justamente en este punto donde debemos hacer una pausa y analizar cuál es el rol de la sociedad en la construcción de una salud pública y accesible para todos, garantizada en las políticas públicas de los distintos países, fundamentalmente de nuestra querida sud américa que se encuentra en un constante resurgir de los conflictos sociales, las crisis económicas que no facilitan esta tarea, más aún, reconociendo que la salud pública no es un tema que esté presente en las agendas de gobierno.

\section{Conclusión}

El derecho a la salud nos abre un horizonte de interrogantes y desafíos para el Siglo XXI. La estructura poliédrica y nodal de este derecho, su interdependencia con otros derechos y bienes públicos que integran el estatuto protectorio de la persona humana de nuestro bloque de constitucionalidad federal, su contenido expansivo y mutativo, son algunas de las variables que lo (re)definen desde una dimensión social, civil, económica y cultural.

Hoy, su incuestionable carácter "fundamental" trae consigo el compromiso y la responsabilidad de hacerlo un derecho practicado, un derecho efectivo. Pero, no debemos soslayar que la realización de un derecho implica un costo y la necesidad de una estructura que asegure su provisión a toda la comunidad. En este sentido, 
somos tributarios de los sistemas de salud, coordinados, fiscalizados y garantizados por un Estado, mediante políticas públicas que aseguren un acceso igualitario a la comunidad y que dicho acceso sea sustentable en beneficio de la misma sociedad reconociendo la necesidad de que la sociedad coadyuve en el cumplimiento de ese objetivo.

En palabras de la Organización Mundial de la Salud (2012), el derecho a la salud obliga a los Estados a generar condiciones en las cuales todos puedan vivir lo más saludablemente posible. Para garantizar esas condiciones, el Estado y los ciudadanos debemos trabajar mancomunadamente, logrando de esa manera, no sólo una salud social, sino además un sistema construido por "todos los todos del todo social" (Frías, 2008).

\section{Referencias}

ARGENTINA. Corte Suprema de Justicia de la Nación. Fallos: 312:318; 314:225; 315:380; 320:196. Disponible en: http://www.csjn.gov.ar/documentos/verdoc.jsp?ID=35650 (Consultado el 20 sep. 2012)

AITH, Fernando. A emergência do Direito Sanitário como um novo campo do Direito. In: ROMERO, Luiz Carlos y DELDUQUE, Maria Célia (orgs.) Estudos de Direito Sanitário: A produção normativa em Saúde. Brasília: Senado Federal : Subsecretaria de Edições Técnicas, 2011.

AVILA PAZ de ROBLEDO, Rosa Angélica del Valle. Las Células Madre. Nuestras Reflexiones sobre el fallo y el caso - Stem Cells. Our Reflections on the Judgment and the Case. Revista de la Facultad, 1(1):132. Nov. 2010.

BARCELLOS, Ana Paula. A Eficácia Jurídica dos Princípios Constitucionais: o Princípio da Dignidade da Pessoa Humana. Rio de Janeiro: Renovar, 2001.

BARZOTTO, Luis Fernando. Apud PFULLER LISBOA, Simone Tatiana. Do Direito à Saúde aos Limites do Controle Judicial dos Atos Administrativos nas Políticas Públicas de Distribuição de Medicamentos. Porto Alegre: 2010. Disponible en http://www.lume.ufrgs.br/bitstream/handle/10183/27342/000764582.pdf?sequence=1 (Consultado el 20 sep. 2012).

BARZOTTO, Luis Fernando. Os Direitos Humanos como Direitos Subjetivos: da Dogmática Jurídica a Ética. In: Claudio Ari Mello. Os desafios dos Direitos Sociais. Revista do Ministerio Público do Río Grande do Sul, Livraria do Advogado: Editora. n. 56, 2005.

BONAVIDES, Paulo. Curso de Direito Constitucional. São Paulo: Malheiros, 2007.

BRASIL. Constituição (1988). Constituição da República Federativa do Brasil: Texto promulgado em 5 de outubro de 1988. Washington : Georgetown University, Political Database of the Americas, Nov. 2008. Disponible en http://pdba.georgetown.edu/Constitutions/Brazil/esp88.html (Consultado el 20 sep. 2012) 
BRASIL. Lei $n^{\circ}$ 8.080, de 19 de setembro de 1990, que dispõe sobre as condições para a promoção, proteção e recuperação da saúde, a organização e o funcionamento dos serviços correspondentes e dá outras providências. Disponible en http://portal.saude.gov.br/portal/arquivos/pdf/lei8080.pdf (Consultado el 20 sep. 2012).

CUNHA, Ricardo Almeida Cunha. O Principio da Proibição do Retrocesso Social e o Direito à Saúde no Brasil. Monografía presentada al curso de Especialización em Derecho Sanitario de la Fundación Oswaldo Cruz - Brasilia, 2010.

FERREIRA DA ROCHA, Silvio Luís. Direito à Saúde. Dos direitos sociais. Belo Horizonte: Fórum Ltda., 2008.

FERREIRA FILHO, Manoel Gonçalves. Direitos Humanos Fundamentais. (8 ed.) São Paulo : Saraiva, 2006.

FRÍAS, Pedro J. "El Poder Legislativo" en EL PODER LEGISLATIVO Aportes para el conocimiento del Congreso de la Nación Argentina. Montevideo: KAS, 2008.

GARCÍA PELAYO, Manuel. Derecho constitucional comparado. Caracas : FMG-P, 2002.

GORDILLO apud MOLINELLI, Juana E. La obligación de no regresividad arbitraria para la tutela efectiva y eficaz del derecho a la salud. LA LEY $2003-\mathrm{F}, 311$.

IX CONFERENCIA INTERNACIONAL AMERICANA. Declaración Americana de los Derechos y Deberes del Hombre. Bogotá, 1948. Disponible en http://www.ucc.edu.ar/portalucc/archivos/File/Derecho/l.D.T./Legislacion internacional /jerarquia constitucional/declaamericanaddydddelhombre.PDF (Consultado el 20 ago. 2012).

JORGE NETO, Nagibe de Melo. O Controle Jurisdiccionaldas Política Públicas: Concretizando a Democracia e os Direitos Sociais. São Paulo: Juspodivm, 2008.

MACEDO, Aruza Albuquerque de y BARRETO E SILVA, Cleyton. A fundamentalidade dos Direitos Sociais. V Encontro de Iniciação Científica do Curso de Direito da Faculdade 7 de Setembro. $[\mathrm{s} / \mathrm{l} ; \mathrm{s} / \mathrm{d}]$ Disponible en http://www.fa7.edu.br/recursos/imagens/File/direito/ic/v encontro/afundamentalidaded osdireitossociais.pdf (Consultado 19 ago. 2012).

MARMELSTEIN, George. Curso de direitos fundamentais. São Paulo: Altas, 2008.

MAPELLI, Reynaldo Junior [et al]. Direito Sanitário. São Paulo : Ministério Público, 2012.

MENDES, Gilmar Ferreira; COELHO Inocêncio Mártires; BRANCO Paulo Gustavo Gonet. Curso de Direito Constitucional. São Paulo: Saraiva, 2008.

MORETTI, Andrezza C [et al]. Práticas Corporais / Atividade Física e Políticas Públicas de Promoção da Saúde. Disponible en http://200.144.190.38/bitstream/handle/2012.1/14435/art MORETTI Praticas 2009.p df?sequence $=1$ (Consultado el 2 oct. 2012)

ORGANIZACIÓN DE NACIONES UNIDAS. Declaración Universal de los Derechos Humanos. 2012. Disponible en http://www.un.org/es/documents/udhr/(Consultado el 20 ago. 2012).

ORGANIZACIÓN MUNDIAL DE LA SALUD. Derecho a la Salud. Nota descriptiva no 323.

Nov. 2012.

Disponible

en 
http://www.who.int/mediacentre/factsheets/fs323/es/index.html (Consultado el 2 oct. 2012).

ORGANIZACIÓN MUNDIAL DE LA SALUD. Comisión Mundial de Determinantes Sociales de la Salud. Determinantes Sociales en Salud. Sep. 2008. Disponible en http://www.minsal.gob.cl/portal/url/page/minsalc//g temas/g determinantes sociales/d eterminantes.html (Consultado el 18 sep. 2012)

ORGANIZACIÓN MUNDIAL DE LA SALUD. Constitución de la Organización Mundial de la Salud. 10/2006. Disponible en: http/l http://www.who.int/governance/eb/who_constitution_sp.pdf. (Consultado el 17 ago. 2012).

SARLET, Ingo Wolfgang. A eficácia dos direitos fundamentais: uma teoria geral dos direitos fundamentais. Porto Alegre: Livraria dos Advogados, 2009.

TORRES, Ricardo Lobo. O mínimo existencial. São Paulo: Renovar, 2008.

TORRES, Ricardo Lobo. O mínimo existencial e os direitos fundamentais. Rio de Janeiro: Revista de Direito Administrativo, 1989.

WINSLOW, C.E. A. The untilled fields of public health. Science, 51(1306): 23-50, Jan. 1920.

ZAVALEY, Nicolás Rodolfo; SOMMER, Maria Agustina Jacinta. Práctica Jurídica de la Salud Pública. El Deber de Cuidar la Salud. Córdoba: Ministerio de Salud de la Provincia de Córdoba, 2011. 